\title{
State of the art of advanced spectral noise and high-precision temperature logging technology utilization in Iraqi oil fields: an integration approach to diagnose wells performance complications
}

\author{
Mohammed Jawad Zeinalabideen ${ }^{1}$ (D) $\cdot$ Mazin Mohlab Al-Hilali ${ }^{2}$ (D) $\cdot$ Andrey Savinkov $^{3}$
}

Received: 28 August 2020 / Accepted: 21 March 2021 / Published online: 2 April 2021

(c) The Author(s) 2021

\begin{abstract}
In this study, an integrated approach of advanced spectral noise and high-precision temperature logging with production logging tool was used for the understanding of leak detection, fluid cross-flow, flow below spinner threshold, packer failure, fluid channeling in patchy and bad cement bond behind the casing, flow quantification in complex SSD completion, production detection and quantification in recirculation intervals in deviated wells. Various case studies from Southern and Northern Iraqi oil fields have been presented in this paper.
\end{abstract}

Keywords Cased-hole logging $\cdot$ Packer leak $\cdot$ Crossflow $\cdot$ Flow behind tubulars $\cdot$ Production logging (PLT) $\cdot$ Spectral noise logging (SNL) $\cdot$ High-precision temperature logging (HPT) and temperature simulation

$\begin{array}{ll}\text { Abbreviations } \\ \text { SNL } & \text { Spectral noise log } \\ \text { HPT } & \text { High-precision temperature log } \\ \text { LFP } & \text { Low-frequency panel } \\ \text { Perf } & \text { Perforation } \\ \text { RFA/RIA } & \text { Reservoir flow (or intake) analysis }\end{array}$

\section{Introduction}

Since 2003, the number of oil wells in Iraq has increased exponentially (Mills 2018) in order to achieve the local production plateau target for each Iraqi oil field. New wells and completion designs, mainly highly deviated and horizontal wells, have been introduced into the Iraqi oil industry that were not widely used in Iraqi oilfields. Evaluating the actual performance of such kind of wells suppress numerous challenges that need an advanced technology.

The conventional method which is available since mid1960s (Wade et al. 1965) to evaluate the downhole well performance using a single spinner with a fluid identification

Mohammed Jawad Zeinalabideen

mohammed.jawad@uokirkuk.edu.iq

1 University of Kirkuk, Kirkuk, Iraq

2 OILSERV, Erbil, Iraq

3 TGT Oilfield Services, Kazan, Russia tools, namely production logging tool (PLT) (Fig. 1), cannot provide the full answer to numerous difficulties/challenges accompanied by well/field aging, deviation and complex completion designs. One of the main challenges for PLT is the well-known water recirculation issue and flow/leakage behind the casing. However, combining PLT and the spectral noise and high-precision temperature is extremely powerful that offers an efficient solution to diagnose well performance complications (TGT Oilfield Services 2017).

The perception of acquisition of the acoustic noise in oil wells dates to 1950 s when Enright (1955) qualitatively defined a procedure of detecting tubing and casing leaks with an acoustic recorder sensing the highest noise levels at leaks. McKinley (1994) presented a noise logging technology as a recording of several frequency acoustic noise channels as am aid to evaluate the flow paths interval.

Yu. St al. (2012) have elaborated the practical use of the spectral noise $\log$ in oil and gas wells. When fluid or gas moves through a media, it produces noise, and the noise comes from both the fluid itself and vibrating elements streamlined by fluid flow. The fluid noise is the result of internal friction and is normally audible in high-speed turbulent flows. It can also be produced by gas bubbling and phase slippage. The reservoir noise is the result of rock grain vibrations induced by the fluid flow. The reservoir noise spectrum depends only on reservoir structure while the volume of noise is a function of fluid type and pressure gradient. 


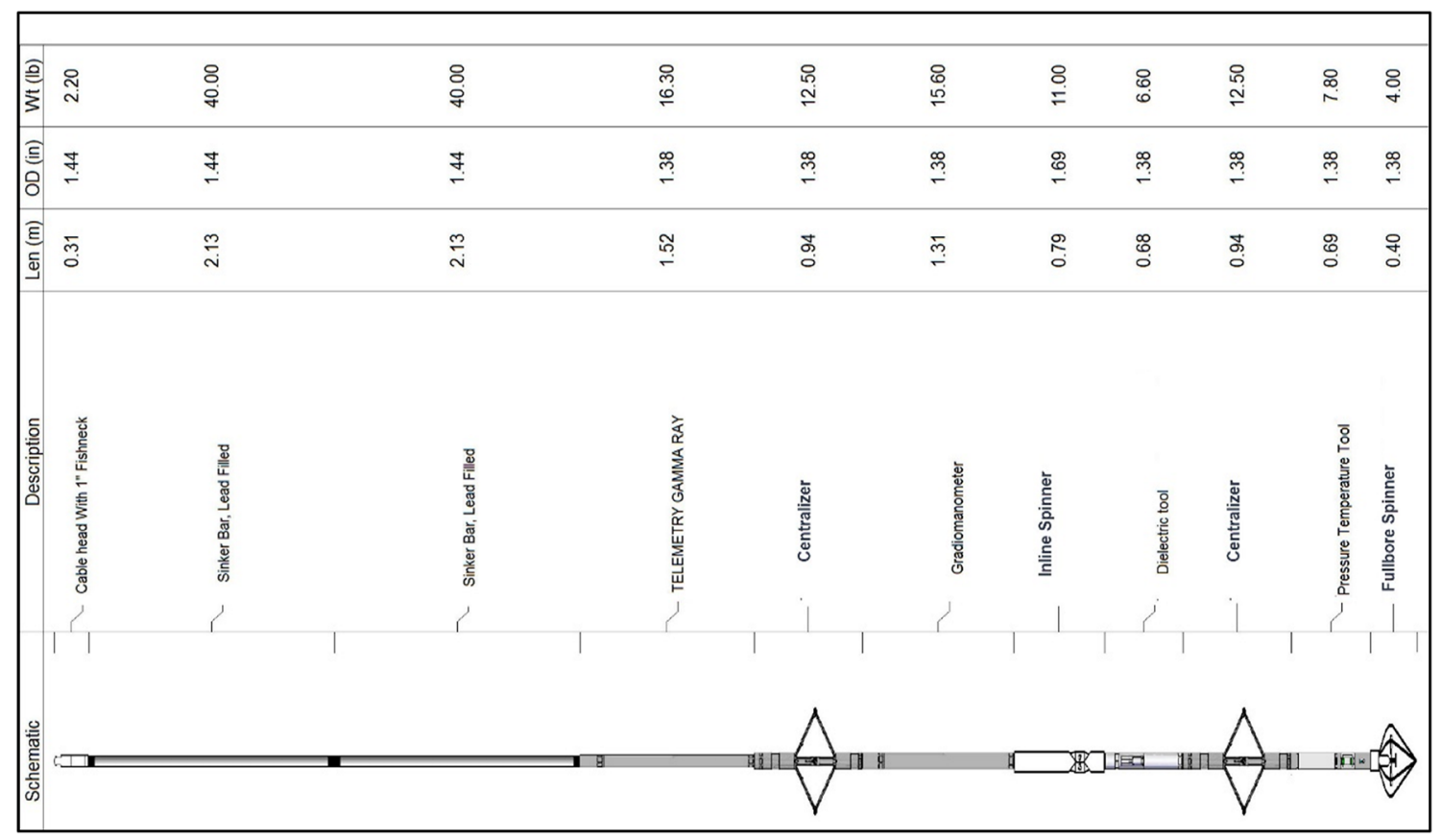

Fig. 1 The PLT conventional string (Courtesy of Oilserv)

This makes SNL a powerful tool to locate active reservoir flow units and tubing/casing leaks.

Arthur et al. (2014) have explained in detail the numerical mathematical modeling to quantitatively evaluating the hydrodynamic pattern acquired by high-resolution temperatures sensors. The original rock temperature distribution is formed by heat flow from the Earth's interior to the boundary conditions at surface. Even though a vertical heat flow can be assumed constant in large areas around wellbore, the non-uniform stratigraphic layering of various rocks with different thermal conductivities often creates a complicated scenario of geothermal profile, far from simplistic representations with straight lines. Since the fluid which flows into the borehole is carrying the geothermal temperature, this provides a huge impact on the blending with upstream flow and cannot be accurately matched until the geothermal model is well defined (Lutfullin 2014).

The combination of operational procedure case by case based on goal, hardware and software solutions of HPT-SNL package is an advanced addition to conventional production logging, which aims to address many downhole flowing and integrity issues that some will be presented in this study.

\section{Spectral noise log (SNL)}

The spectral noise logging tool is designed to record sound in a wide frequency range. The key component of the SNL tool is a highly sensitive hydrophone, which is a piezo crystal sensor placed in an oil-filled chamber. Oil reduces the density difference between the wellbore fluid and the sensor's environment, thus minimizing the reflection of acoustic waves from the interface and maximizing the sensor's sensitivity (TGT Oilfield Services 2016).

The recorded time-domain data are written to the tool's internal memory using high-frequency analogue-to-digital converters. Further analysis of SNL data is conducted after reading the data from the tool. In the spectral domain, the recorded noise logging data fall in a wide frequency range from $8 \mathrm{~Hz}$ to $58.5 \mathrm{kHz}$. A battery pack contained in the tool can power all its electronic components for a continuous period of $48 \mathrm{~h}$. The tool operates in memory mode on slickline, wireline, tractor or coiled tubing and can be used in both vertical and horizontal wells. All components of the tool are made of high strength materials, and its electronic circuits are assembled from high-temperature components. As a result, the SNL tool can be used to survey wells at temperatures of up to $150{ }^{\circ} \mathrm{C}$ and pressures of up to $60 \mathrm{MPa}$. The tool housing is made of titanium and can be used to log wells containing hydrogen sulfide (H2S), and technical specifications of the SNL are given in Table 1.

The SNL panel (Fig. 2) shows noise volume distribution from less than $300 \mathrm{~Hz}$ (left side of the panel) to $30 \mathrm{kHz}$ (right side of the panel). The color palette shows red for highest noise volumes and then gradually goes through yellow, green and blue for lower noise volumes with white denoting a noise below the tool sensitivity threshold, and the spectra distinctly show matrix flow as a noise peak 
Table 1 SNL and HPT tools specifications

\begin{tabular}{lll}
\hline Measurement type & $\mathrm{SNL}$ & $\mathrm{HPT}$ \\
\hline Accuracy & $3-58,500 \mathrm{~Hz}$ & $0.1^{\circ} \mathrm{C}\left(0.36^{\circ} \mathrm{F}\right)$ \\
Dynamic range & $0-90 \mathrm{~dB}$ & $\mathrm{~N} / \mathrm{A}$ \\
Resolution & $115 \mathrm{~Hz}$ & $0.001{ }^{\circ} \mathrm{C}\left(0.0018^{\circ} \mathrm{F}\right)$ \\
Pressure rating & $9000 \mathrm{psi}$ & $9000 \mathrm{psi}$ \\
Temperature rating & $0-150{ }^{\circ} \mathrm{C}\left(32-305^{\circ} \mathrm{F}\right)$ & $0-150{ }^{\circ} \mathrm{C}\left(32-305^{\circ} \mathrm{F}\right)$ \\
Length & $0.816 \mathrm{~m}$ & $0.44 \mathrm{~m}$ \\
Weight & $7 \mathrm{~kg}$ & $2.5 \mathrm{~kg}$ \\
Diameter & $1.65 \mathrm{in}$ & $1.65 \mathrm{in}$ \\
\hline
\end{tabular}

around $15 \mathrm{kHz}$. It is often paired with one or two peaks around $3-5 \mathrm{kHz}$ originating from the fracture flow. Also, you can see noise produced by well completion elements, such as tubing and casing, perforations, faults and fractures in the frequency bands as shown in Fig. 2 (Maslennikova et al. 2012).

Various fluids differ in noise volumes they produce while flushed through the porous media. But the shape of noise spectrum is not noticeably affected by the fluid type and can be mostly defined by the pore structure.
The only exception is gas, as the gas has much better penetrating abilities than water/oil so that the gas noise covers the whole spectrum range as it induces the vibration of much wider range of rock grains and pore throats. Due to this reason, the gas flow is so clearly seen in the spectra (Maslennikova et al. 2012).

\section{High-precision temperature log (HPT)}

The temperature sensor is a platinum-wire thermistor. The sensor resistance changes with ambient temperature, and the changing output voltage of the sensor is fed to the input of an analogue-digital converter. Then, the temperature is calculated through a calibration (Aslanyan 2013).

The HPT is special engineered wireline tool that differs from the conventional temperature tool that runs usually with PLT; refer to Table 1 for HPT tool specification.

The main issue in temperature logging today is not the sensor sensitivity but the sensor response time and depth correlation. The response time shows how fast the sensor responds to fluid temperature changes, although tool manufacturers do not always publish this parameter. Moreover, the response of the tool is normally longer than the specified

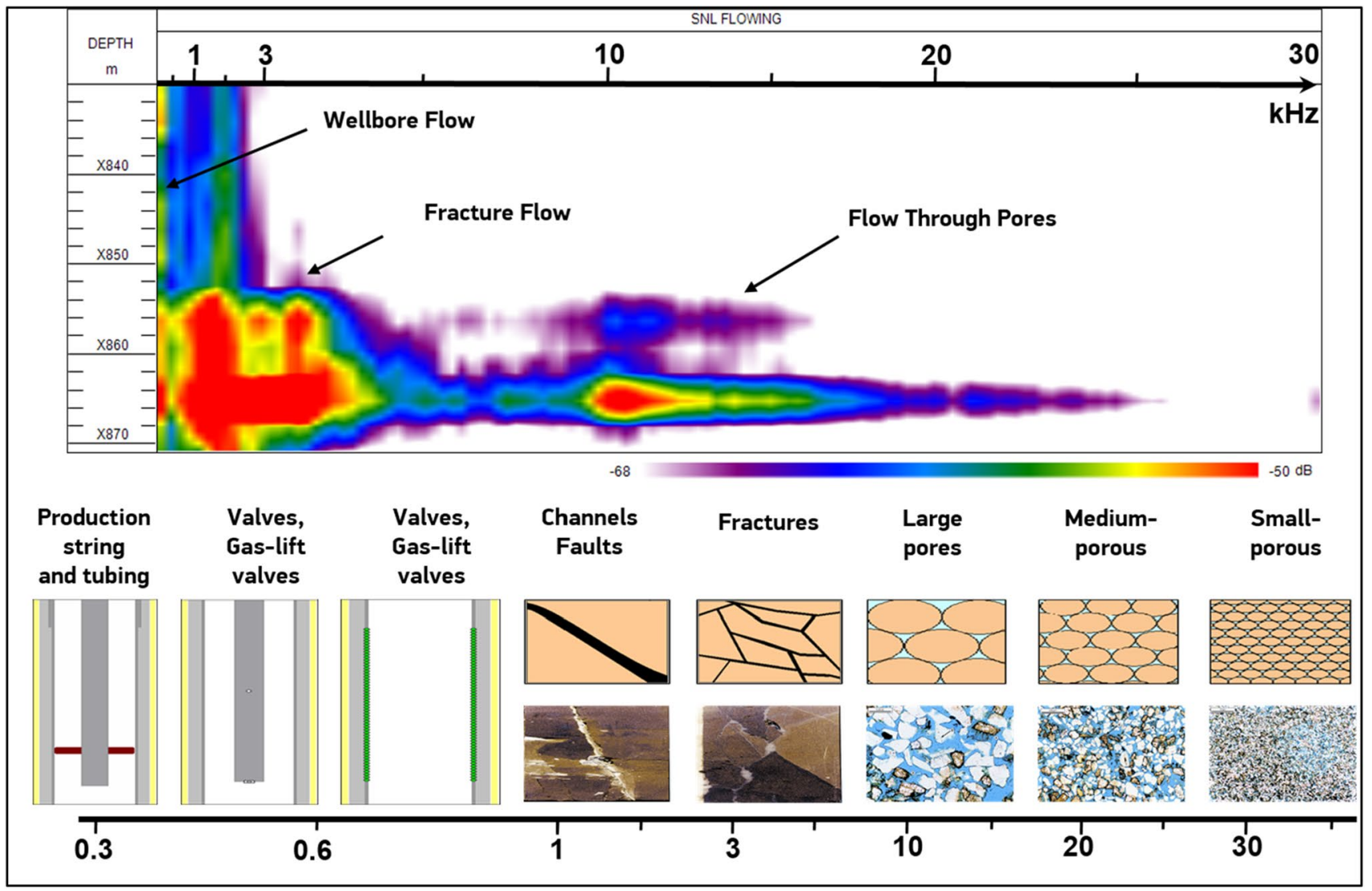

Fig. 2 The SNL panel shows noise distribution from less than $300 \mathrm{~Hz}$ to $30 \mathrm{kHz}$ 
time response of the sensor because the sensor's housing is not fully transparent to fluid flow. This increases the time needed for a temperature balance to be reached between the sensor/tool and borehole fluid. For this reason, the best temperature tools are designed with maximum exposure of the temperature sensor (Arlen Sarsekov et al. 2016).

The differences between the low-resolution conventional temperature log and the high-precision temperature log can be illustrated in Fig. 3 (Maslennikova et al. 2012). The lowresolution temperature log records are blurrily in comparison with HPT logs which correlates perfectly with the top and bottom of the perforated interval. Due to longer response times, low-quality records may depend on the tool location inside the hole and cannot even be reproduced under identical temperature conditions. This apparently explains why the flowing and transient temperatures in Fig. 3 (left panel) deviated from the static log (red color), which can be mistakenly interpreted as behind-casing channeling below the perforations. In fact, the HPT logs shown in the right panel merge below the perforations with no signs of channeling. The instability of low-resolution logging is illustrated in the left panel by transient logs that occasionally intersect each other and the static log. In contrast, the HPT logs follow in strict order.

\section{Temperature modeling}

Temperature logging conducted throughout the wellbore is one of the most informative well surveying techniques widely used for qualitative analysis of processes in wells and reservoirs. For a long time, it was impossible to analyze temperature logs quantitatively because of the thermo-hydrodynamic complexity of the well-reservoir system. As computer technology developed, temperature measurements came into use to quantify inflow and injection and unwanted injection and production as well as to analyze well integrity issues including channeling. The TERMOSIM $^{\mathrm{TM}}$ software application (Arthur Aslanyan et al. 2013) is designed for temperature and hydrodynamic simulations. It quantitatively analyzes temperature $\log \mathrm{s}$ and can be used for the following applications:

- For injectors

- Injection profiling across flowing reservoir units.

- Quantification of injection loss outside intervals of interest.

- Identification and quantification of behind casing channeling and wellbore crossflows including those into unperforated zones.

- Quantitative characterization of historical injection zones.

- For producers

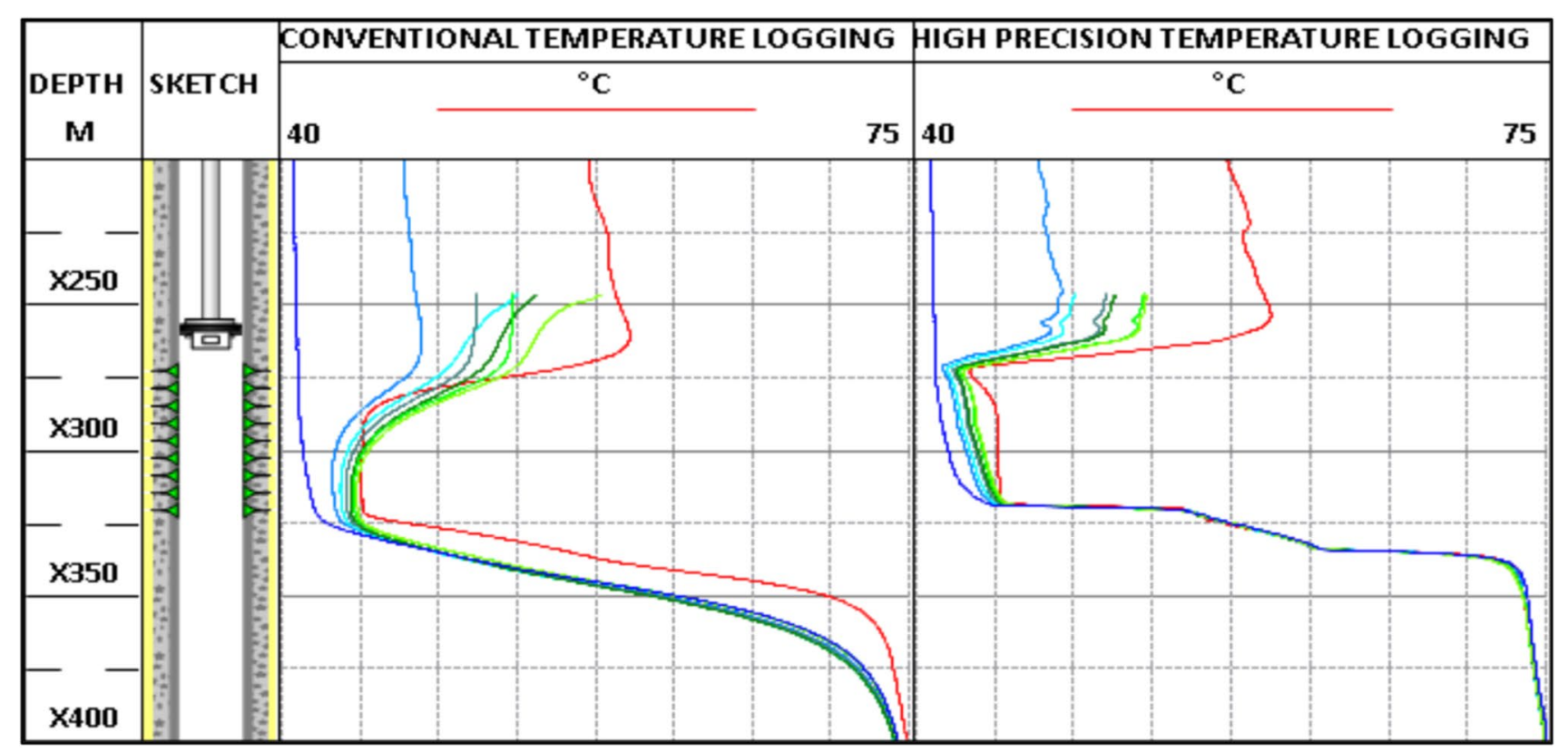

Fig. 3 Conventional temperature sensor vs. HPT sensor 
- Production profiling across flowing reservoir units.

- Identification and quantification of behind casing channeling and wellbore crossflows including those from unperforated zones.

- Location of zones of water breakthrough from nearby injectors.

The TERMOSIM ${ }^{\mathrm{TM}}$ software numerically solves the problems of flow hydrodynamics and heat exchange between the wellbore fluid, completion components, surrounding anisotropic rocks and reservoirs. TERMOSIM ${ }^{\mathrm{TM}}$ can flexibly tune a multi-parameter thermo-hydrodynamic model to match simulated and measured temperatures. It operates in two modes:

Injection mode is for injection temperature modeling, and production mode is for production temperature modeling. The simulation is based on the assumption that fluid and gas flow is in the reservoir radially from and to the well. It also takes into consideration the thermodynamic effects caused by fluid and gas flows through a reservoir, behind casing and along the wellbore as well as wellbore and behind-casing cross-flows.

\section{Reservoir flow (and intake) analysis (RFA and RIA)}

SNL is a powerful technique for reservoir flow analysis due to its ability to locate active reservoir flow units. Although it cannot reliably calibrate noise volume in terms of flow rates, noise is a complex function of several flow parameters, most of which, including differential pressure, fluid type and reservoir rock properties, are unknown. SNL data are visualized in the SNL data panel to locate active flow units that can also be used as an input for TERMOSIM ${ }^{\mathrm{TM}}$ to start a matching procedure. The integration of temperature simulation and spectral noise logging provides a unique technique for volumetric assessment of behind-casing flow profile (TGT Oilfield Services DMCC, 2016,"Well Log Analysis Handbook" 2016).

\section{Iraq case study \#1: detection of major flow behind casing in fractured carbonates}

A PLT tool string has been run in tandem with SNL-HPT tool (Fig. 4) in 60 degree deviated well targeting fractured carbonate formation, and the objectives of the run were as follows:

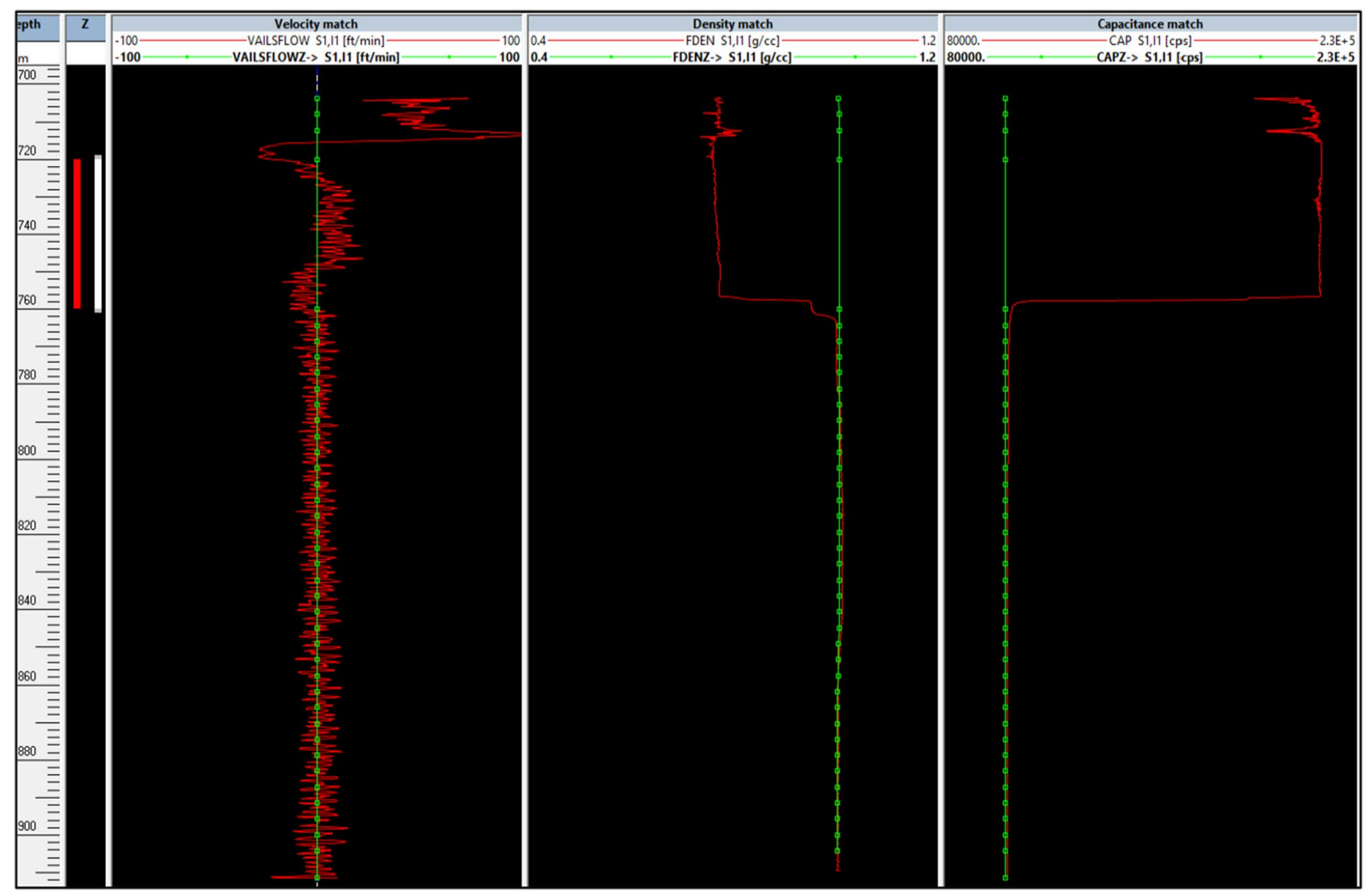

Fig. 4 IRAQ case study \#1 PLT analysis results at shut-in condition 
1. Evaluate the production profile across the perforated.

2. Detect water entry point.

3. Detect any possible flow behind casing.

4. Fluid Typing at downhole conditions.

5. Pinpoint the static fluid contact in wellbore.

The logging string was deployed in flowing and shut-in conditions, and outcomes of PLT analysis in integration with SNL-HPT evaluation were as follows:

- During shut-in condition: PLT data and analysis show minor wellbore cross-flow between the perforations (Fig. 4), while the SNL-HPT indicates clear temperature anomaly associated with acoustics noise, indicating active cross-flowing behind the casing (Fig. 6).

Noises with frequencies from 2 to $4.5 \mathrm{kHz}$ are presented throughout the logging zone; these were associated with running GR sensor. (Due to this, SNL panels were also used for interpretation.)

In the zone X772 m-X841 m, noises with frequencies from 2 to $5 \mathrm{kHz}$ are typical crossflow signals. Also, at this zone have other noises from 10 to $12 \mathrm{kHz}$ typical of flow through micro-fissures that have likely been formed after acid treatment and it may happen that there were natural fractures within this interval.

- During flowing condition: The same response of SNLHPT indicating the cross-flow behind casing (below the perforated zone) remains active, while the PLT analysis (Fig. 5) indicates the main entry to the wellbore mostly occurs across the most lower perforation part (Fig. 6).

\section{Iraq case study \#2: reservoir inflow/intake analysis for injector}

SNL-HPT log was run in flowing and shut-in conditions in vertical well to make reservoir intake analysis (RIA), meanwhile a PLT job done in flowing conditions only; the main goals were as follows:

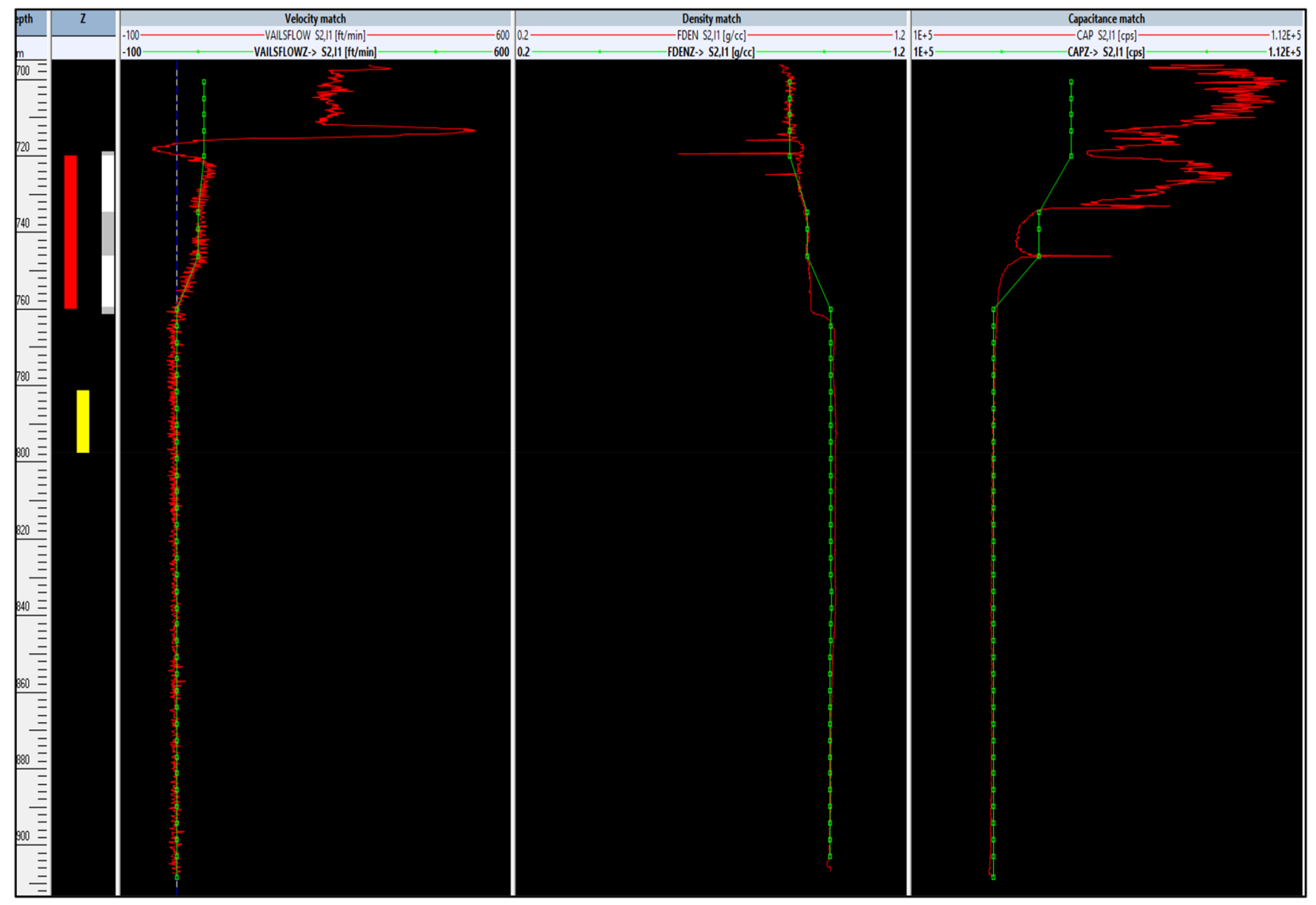

Fig. 5 IRAQ case study \#1 PLT analysis results at flowing condition 


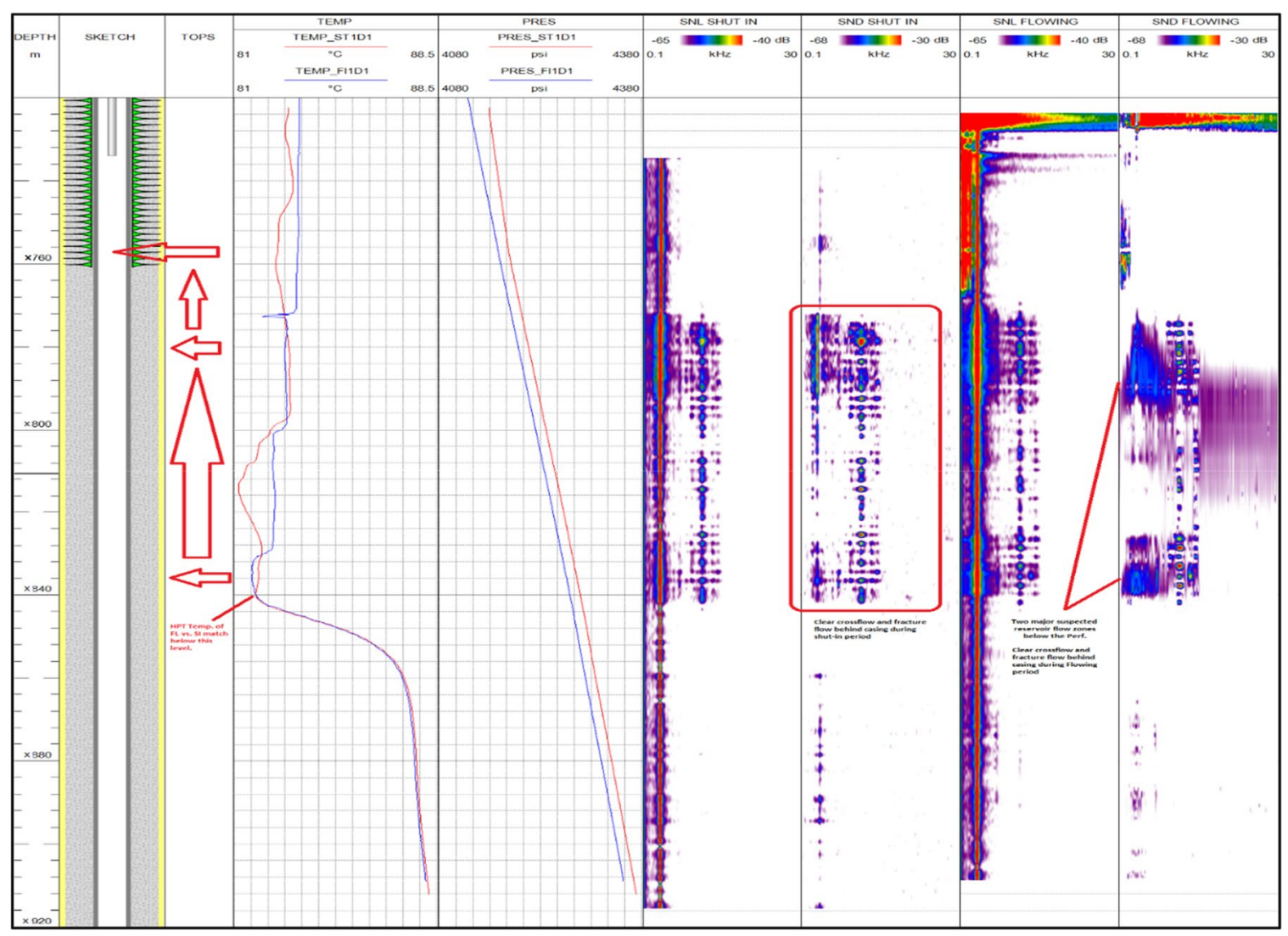

Fig. 6 IRAQ case study \#1 SNL-HPT data in shut-in and flowing conditions

1. Evaluate the injection profile across the perforated interval

2. The type of injection paths is its fracture and/or matrix paths.

The PLT data were good enough to evaluate the wellboreto-perforation injection profile (Fig. 7) for rate that above the spinner threshold. The reservoir intake analysis (RIA) for injection profile (Fig. 8) has shown that the PLT misses low-rate injection to the second perforation interval; also the RIA indicates clear intake behind the casing above the first perforation and below the bottom perforation intervals.

The maximum cooling anomalies were observed in the interval X370.7-X389.0 m, which indicates the maximum injection into this interval (QZI Track in Fig. 8). The temperature modeling showed $87.9 \%$ of total fluid intake in this zone, while the PLT analysis gave different intake profile from wellbore to perforation for bottom perforation (QZI Track in Fig. 8). This does not mean the PLT data is wrong, but it indicated only fluid distribution in the perf-face but not in the formation where the HPT log can measure in formation itself further behind the casing.

The SNL log was used to understand the injection paths category, which indicates frequency ranges of fracture/ matrix paths, as illustrate in Table 2. 


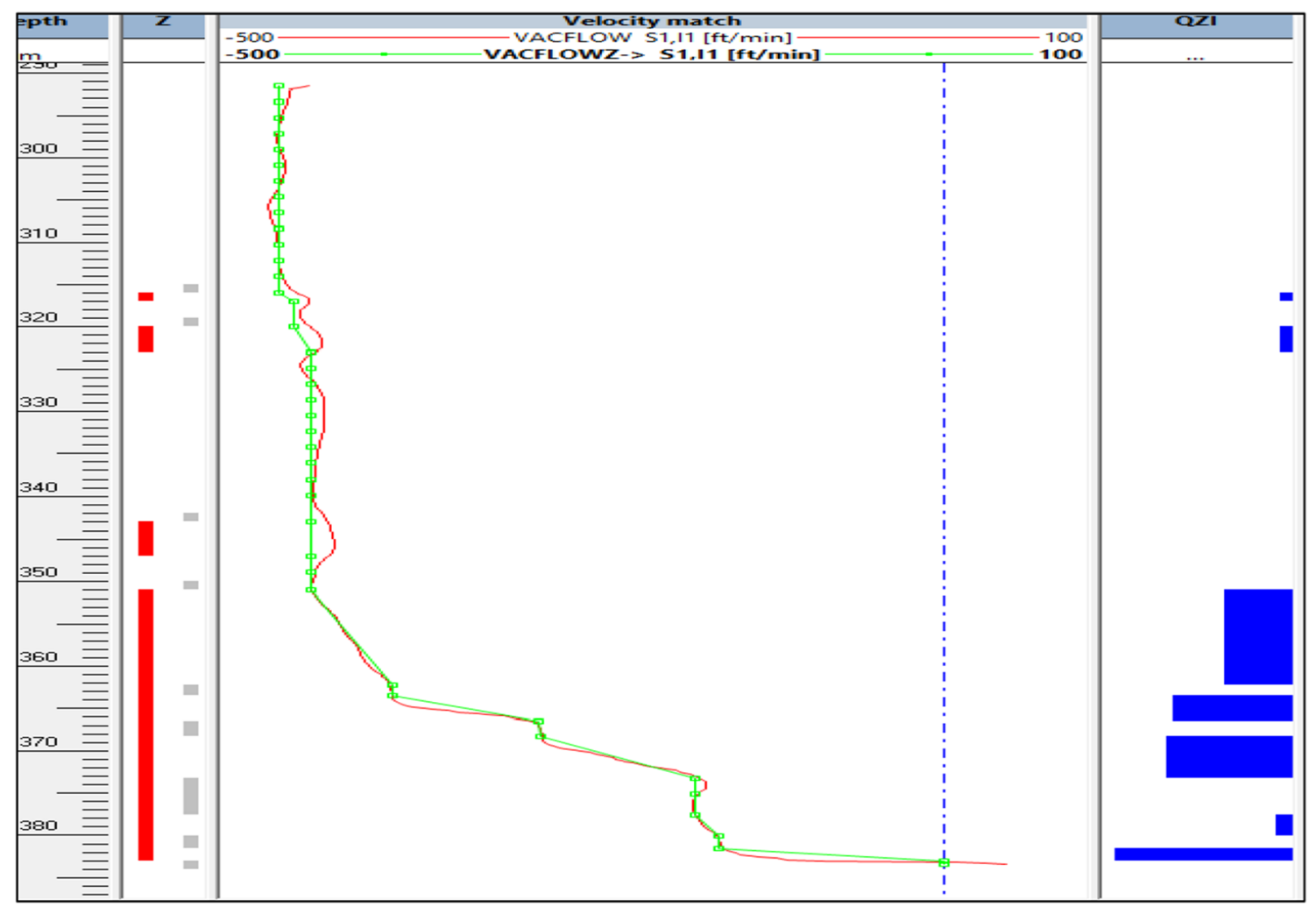

Fig. 7 IRAQ case study \#2 PLT analysis results in flowing condition

\section{Iraq case study \#3: confirm gas entry point and minor channeling detection}

SNL Logging ran in vertical well to pinpoint the source of high gas production and confirm the cement integrity behind the casing.

Flowing SNL panel featuring $117-30,000 \mathrm{~Hz}$ capturing noise generated by wellbore flow is shown in Fig. 9, channeling in the cement and reservoir flow. The low-frequency panel (LFP Flowing) features $8-2000 \mathrm{~Hz}$ noise focusing on noise generated by wellbore flow and fluid entering through the perforations.

SNL flowing and LFP flowing detected noise caused by fluid flow within the interval X522-X544 m that can be divided into three smaller intervals:
- The interval X522-X528 m (above the perforated interval) with low-frequency $1.2-4.2 \mathrm{kHz}$ noise indicates downward fluid channeling behind casing to the perforation. This noise extends to X522 m and suggests there is only a minor amount of flow migrating behind the casing from above the perforation zone.

- The interval X528.2-X537.0 has high-intensity noise through frequencies $0.01-20 \mathrm{kHz}$. The noise pattern identified by SNL indicates gas inflow by matrix/fracture flow. Gas flow has a specific signature in the noise spectrum and much better penetration capabilities than liquids. Therefore, gas generates noise in a wide frequency range through vibrations of rock grains of various sizes and pore throats. The LFP panel in this zone indicates major portion of production enters the perforation. 


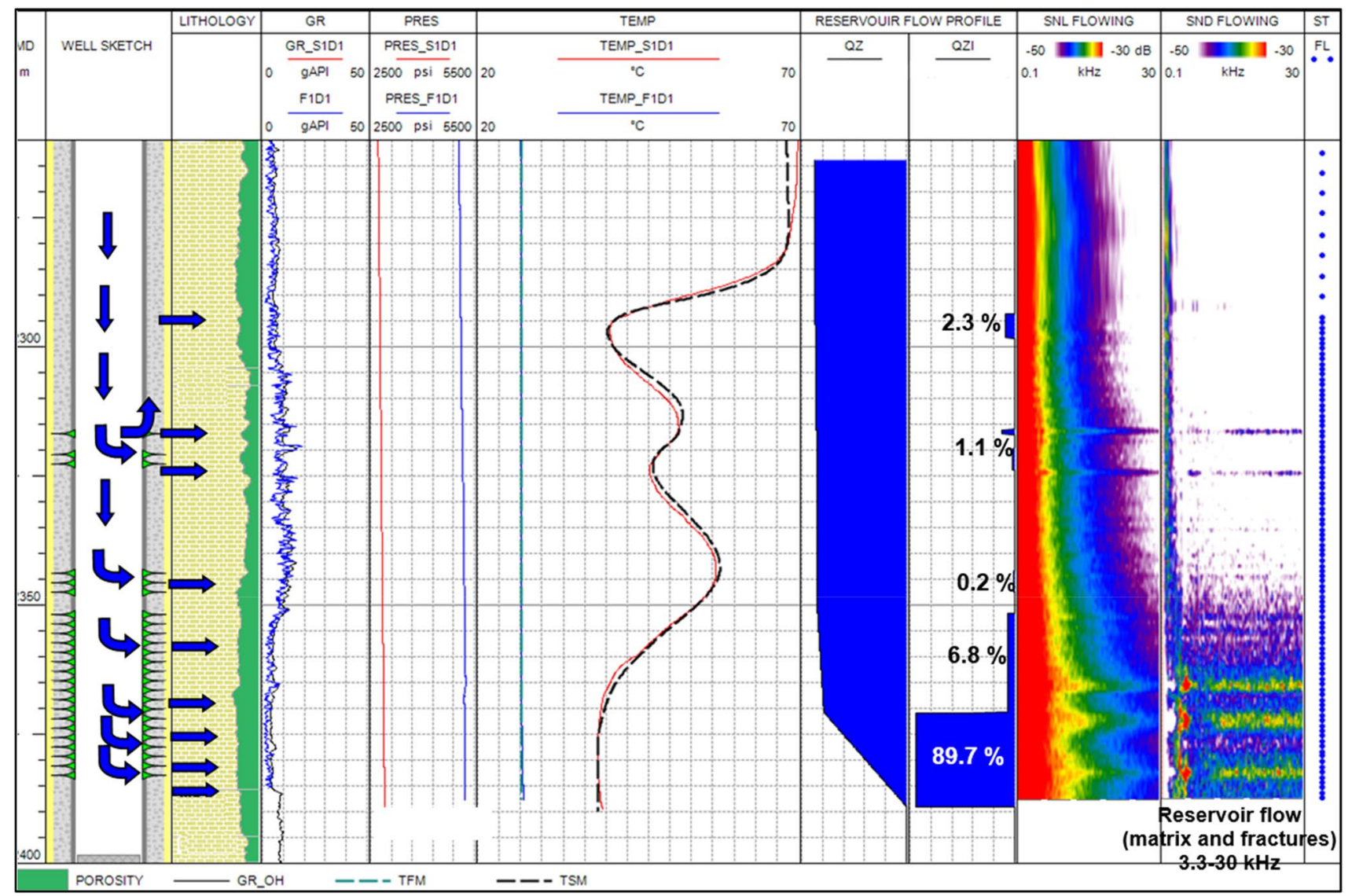

Fig. 8 IRAQ case study \#2 SNL-HPT data in flowing conditions with RIA

Table 2 Noise distribution according to SNL data

\begin{tabular}{llllll}
\hline Condition & $\begin{array}{l}\text { Top } \\
\mathrm{m}\end{array}$ & $\begin{array}{l}\text { Bottom } \\
\mathrm{m}\end{array}$ & $\begin{array}{l}\text { Frequency range } \\
\mathrm{kHz}\end{array}$ & $\begin{array}{l}\text { Max amplitude } \\
\mathrm{dB}\end{array}$ & Flow type \\
\hline Flowing & $\mathrm{X} 316.0$ & $\mathrm{X} 318.0$ & $6.0-30.0$ & -40 (low) & Matrix \\
Flowing & $\mathrm{X} 324.0$ & $\mathrm{X} 325.0$ & $3.0-30.0$ & -40 (low) & Fracture flow/matrix flow \\
Flowing & $\mathrm{X} 351.0$ & $\mathrm{X} 362.0$ & $0.1-30$ & -40 (low) & Fracture flow/matrix flow \\
Flowing & $\mathrm{X} 362.0$ & $\mathrm{X} 387.5$ & $1.5-30.0$ & -20 (high) & Fracture flow/matrix flow \\
\hline
\end{tabular}

- The interval X537-X544 m with frequency 0.01$0.88 \mathrm{kHz}$ noise featured in the LFP Flowing indicates minor portion of fluid entering through the perforation interval. The absence of higher-frequency noise in the SNL Flowing panel indicates only minor inflow from this interval, with no sign of matrix flow.

\section{Conclusions}

Spectral noise and high-precision temperature logging technology (Fig. 10 and Table 1) have been used in several Iraqi oil fields to diagnose many downhole issues and give an integrated picture in combination with other logging tool to evaluate well injection and production performance. 


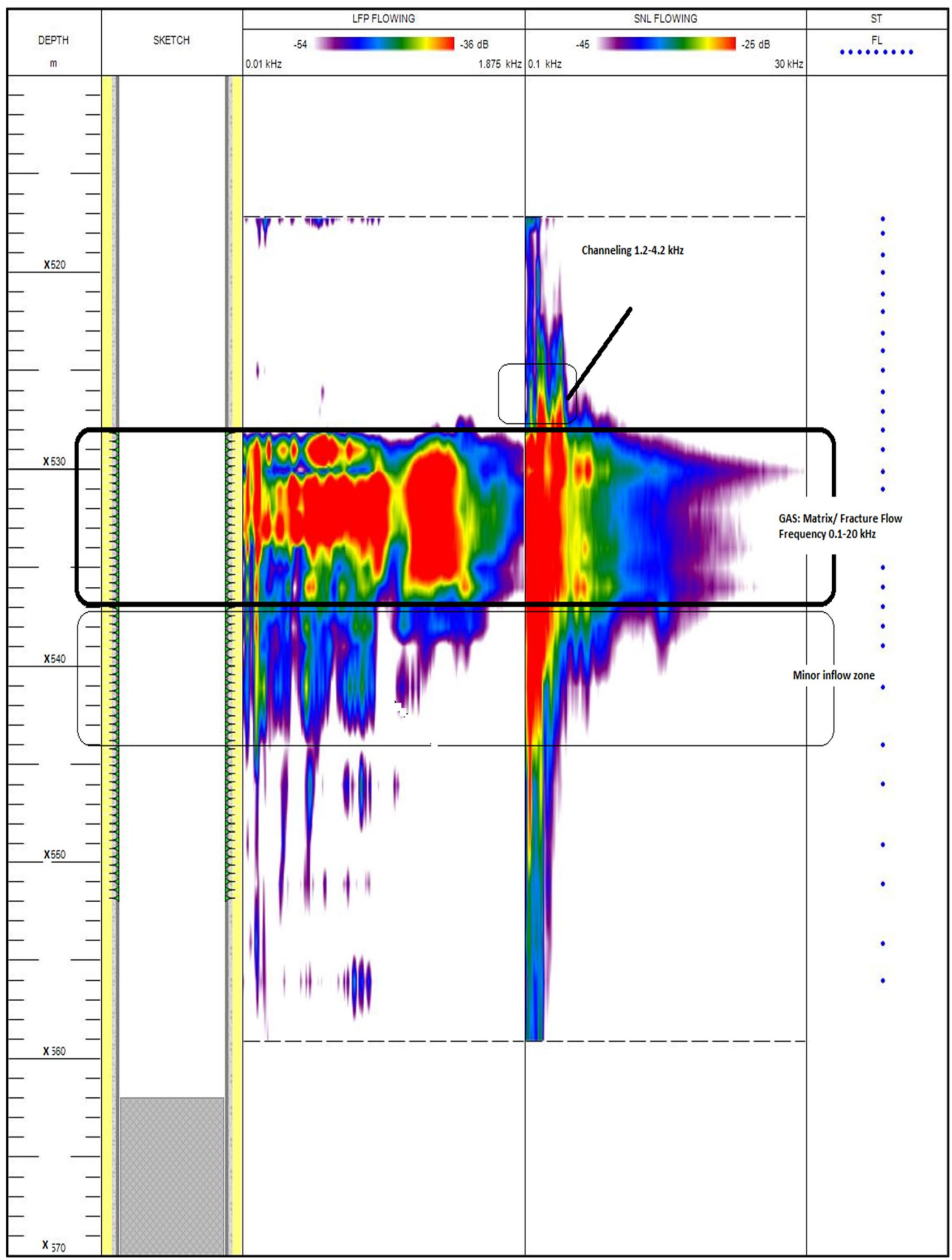

Fig. 9 IRAQ case study \#3 SNL data in flowing conditions 
Fig. 10 SNL-HPT tool diagram (Wade et al. 1965)

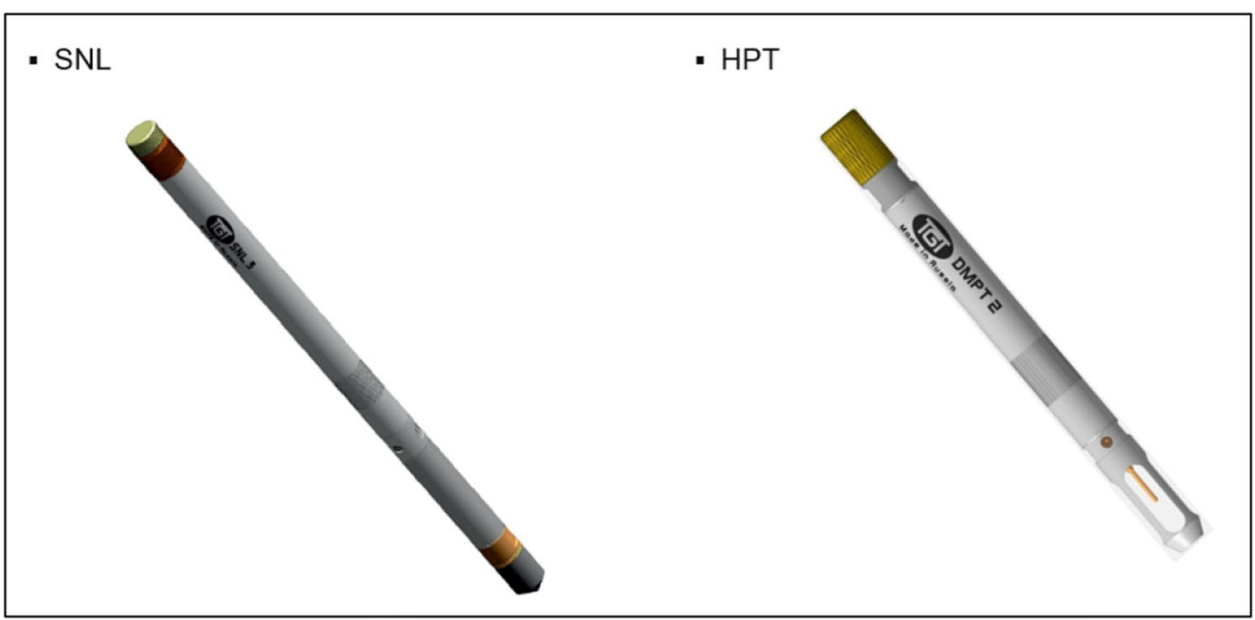

Cases presented have shown some of the benefits of this kind of advance logging tools and how successfully achieve the required goals per each practical case.

It is recommended to run SNL-HPT tool frequently with PLT string in rig and rigless operations to come up with better operational decisions.

Funding This study was implemented based on the technical experience of the authors and no funding was collected by any party.

Open Access This article is licensed under a Creative Commons Attribution 4.0 International License, which permits use, sharing, adaptation, distribution and reproduction in any medium or format, as long as you give appropriate credit to the original author(s) and the source, provide a link to the Creative Commons licence, and indicate if changes were made. The images or other third party material in this article are included in the article's Creative Commons licence, unless indicated otherwise in a credit line to the material. If material is not included in the article's Creative Commons licence and your intended use is not permitted by statutory regulation or exceeds the permitted use, you will need to obtain permission directly from the copyright holder. To view a copy of this licence, visit http://creativecommons.org/licenses/by/4.0/.

\section{References}

Aslanyan A, Wilson M, Al Shammakhy A, Aristov A (2013) Evaluating injection performance with high-precision temperature logging and numerical temperature modelling. In: SPE-166007-MS, Abu Dhabi, UAE
Aslanyan A, Aslanyan I, Salamatin A, Karuzin A, Fesina Y, Zaripov I, Skutin V, AL Ghafri Z, AL Yarabi M, AL Maharbi A (2014) PDO, numerical temperature modelling for quantitative analysis of lowcompressible fluid production. SPE 172090

Enright RJ (1955) Sleuth for Down-Hole Leaks. Oil Gas J

Lutfullin AA, Abdrahimov AR, Shigapov IN, Aslanyan IY, Aslanyan AM, Kuzyutin RK, TGT Oilfield Services (2014) Identification of behind-casing flowing reservoir intervals by the integrated highprecision temperature and spectral noise logging techniques. SPE 171251-MS, Moscow, Russia

Maslennikova YS, Bochkarev VV, Savinkov AV, Davydov DA (2012) Spectral noise logging data processing technology. In: SPE 162081, Moscow, Russia

McKinley RM (1994) Temperature, radioactive tracer, and noise logging for injection well integrity. United States Environmental Protection Agency, United States

Mills R (2018) A new hope: Iraq oil's way forward. Al-Bayan Center Publications Series, Iraq

Sarsekov A, Khalifa Al-Neaimi A, Zhao W, Saber M, Tauk R, Volkov M, Makhiyanov R, Barghouti J, Vishnu R (2016) Identification of thief zones and water allocation in dual water injectors with temperature and spectral noise logging. In: SPE-183491-MS, Abu Dhabi, UAE

TGT Oilfield Services DMCC (2016) Well Log Analysis Handbook

TGT Oilfield Services (2017) Spectral Noise Logging. SNL-HD White paper

Wade RT, Cantrell RC, Poupon A, Moulin J (1965) Production logging-the key to optimum well performance. J Pet Technol 17(2):137-144

Publisher's note Springer Nature remains neutral with regard to jurisdictional claims in published maps and institutional affiliations. 